ECONOMía Teoría y PRÁctica Nueva Época, número 48, enero-junio 2018, pp. 9-38, http://dx.doi.org/10.24275/ETYPUAM/NE/482018/Pelaez

\title{
Inconsistencia del equilibrio parcial en la teoría del valor y su consistencia macroeconómica* ${ }^{2}$ \\ Inconsistency of Partial Equilibrium Analysis Into the Theory of Value and its Macroeconomics Consistency
}

\begin{abstract}
José Guillermo Peláez Gramajo**
\section{RESUMEN}

Este trabajo tiene dos objetivos, primero, mostrar que el análisis del equilibrio parcial no tiene sentido en la teoría del valor, y segundo, mostrar su potente utilidad en los agregados macroeconómicos. El análisis de un solo mercado, asumiendo la cláusula filosófica ceteris paribus, es engañoso y simplista, pues, cuando varía el precio en un mercado, el ingreso residual influye en el resto de éstos, además, la existencia de mercancías complementarias y sustitutas también refleja la interdependencia general y la naturaleza holística del sistema económico: el todo es más que la suma de las partes, obviar este hecho conduce a la trampa de la falacia de composición. Cournot, al criticar a los economistas clásicos, efectuó un análisis significativo de los precios relativos, así, introdujo la plata como numerario. El pleno desarrollo de la incorporación del dinero dentro de la teoría del valor es mérito de Marx, quien introdujo el oro como moneda mercancía que tiene valor intrínseco. Sraffa efectuó la crítica seminal al análisis del equilibrio parcial de Marshall por medio de las dos leyes de rendimientos (crecientes y decrecientes) cuyos efectos provocan profundas distorsiones en la simetría de la oferta y la demanda descrita en un mercado aislado. Al criticar el análisis del equilibrio parcial, Arrow y Hahn muestran que, el análisis del equilibrio no puede ser fragmentado en equilibrios separados porque la existencia de un mercado implica que, por lo menos, existe un mercado adicional, estos autores demuestran que, si se asume la ficción de una economía de dos bienes, el análisis gráfico de un mercado muestra el equilibrio y desequilibrio general, pues el precio del mercado ausente es el numerario. Sin embargo, Arrow y Hahn apuntan acertadamente que, cuando se aplica el teorema Leontief-Hicks, es posible el análisis del equilibrio parcial, el cual tiene relevancia teórica y empírica para una economía con múltiples mercados.
\end{abstract}

Palabras Clave: Equilibrio general, equilibrio parcial, desequilibrio, precio relativo, sustitutabilidad, complementariedad, índice de precios, numerario, microeconomía, macroeconomía.

Clasificación JEL: B310; B410; B460; D500

\begin{abstract}
This paper has two aims, to point out that partial equilibrium analysis does not make sense into the theory of value; and to show its utility concerning the macroeconomic analysis. The analysis of one single market, assuming ceteris paribus philosophical clause, is simplistic and misleading, since a change on market price, modifies residual disposable income to finance purchases on the rest of the markets; besides, the existence of substitutability and complementariness, between commodities, also reflect the general interdependence between markets as well as the holistic nature of the economic system: the whole is more than the aggregate of the parts, to elude this fact leads to the trick of the fallacy of composition. Thus, Cournot's criticism to classical economists becomes a meaningful analysis on relative prices as a result of a market trading process; thus, he introduces silver as numeraire. Nonetheless, the full development regarding the incorporation of money into the theory of value comes from Marx, who introduced currency as commodity money (gold), which has intrinsic value. Sraffa made the seminal criticism to Marshall's partial equilibrium analysis by means of the two laws of returns (increasing and diminishing), whose effects have profound disturbs on the symmetry of supply and demand that is described into isolated markets. Arrow and Hahn pointed out that the equilibrium analysis cannot be fragmented into separated equilibriums; the existence of one market implies, at least, the existence of an additional market. By assuming the fiction that the economy has two commodities, the graphic analysis of one single market shows the general equilibrium and disequilibrium, since the price of the absent market works as numeraire. Nevertheless, by means of Leontief-Hicks theorem, it is possible the equilibrium analysis within the framework of great economic aggregate tendencies, that has theoretical and empirical relevance and importance for the assessment of the economy. Keywords: General equilibrium, partial equilibrium, disequilibrium, relative price, substitutability, complementariness, index price, numeraire, microeconomics, macroeconomics.
\end{abstract}

JEL Classification: B310; B410; B460; D500

* Una versión preliminar de este artículo fue presentada en 43rd Annual Meetings of the History of Economics Society, Duke University, Durham, North Carolina, June 17-20, 2016. Agradezco especialmente al profesor Michel de Vroey (University of Louvain) -quien fungió como Discussant-, las sugerencias a mi presentación. Este trabajo también fue sometido al arbitraje de tres réferis anónimos; agradezco a uno de ellos las múltiples sugerencias de forma, así como los cambios de fondo que surgieron en la versión final, a la luz de sus múltiples interrogantes.

** Universidad Autónoma Metropolitana. Correo electrónico: jgpg@correo.azc.uam.mx. ORCID: 0000-0001-6764-8889 


\section{INTRODUCCIÓN}

Esta investigación tiene dos objetivos: demostrar que el análisis del equilibrio parcial no tiene sentido teórico en el marco de la teoría del valor, y exponer que dicho análisis tiene sentido teórico y empírico en los agregados macroeconómicos. Un objetivo suplementario es aclarar que Cournot no fue un autor que utilizó el equilibrio parcial. El adjetivo general hace referencia a que es imposible hablar de equilibrio acerca de una mercancía particular, en virtud de que el equilibrio económico no puede ser fragmentado en equilibrios separados de mercancías individuales, la existencia de un mercado particular implica, al menos, la existencia de un mercado adicional. Podría argumentarse, asumiendo la cláusula filosófica ceteris paribus, que es posible el análisis del equilibrio de un solo mercado cuando todos los otros precios permanecen constantes.

Este artículo muestra que el anterior es un argumento simplista y engañoso, por dos razones evidentes. La primera razón es la existencia de mercancías complementarias y sustitutas, esa doble peculiaridad pone de manifiesto la interdependencia general de los mercados y su naturaleza holística, pues la variación del precio de una mercancía afecta no sólo la oferta y la demanda de ésta, sino la oferta y la demanda de las mercancías que la complementan y/o sustituyen. La segunda razón, estrechamente vinculada con la anterior, obedece a que la variación de cualquier precio genera tácitamente una variación del ingreso residual disponible para la compra de todas las demás mercancías, por lo tanto, las demandas y ofertas de las mercancías tienen una interdependencia general.

Debido a la ausencia del dinero en la teoría dominante-teoría subjetiva del valor: teoría del valor de uso ${ }^{1}$ - las magnitudes económicas son precios y cantidades ¿Por qué? Porque en virtud de la ausencia de moneda el precio relativo expresa las cantidades que se intercambian de un bien por otro: economía de trueque. Así, un precio se define como tasa de cambio entre dos mercancías con respecto a transacción de cantidades, $\frac{p_{i}}{p_{j}}={\frac{\Delta x_{j}}{\Delta x_{i}}}^{2}$, que constituye un enunciado estándar de la teoría

${ }^{1}$ En la teoría dominante no hay valor de cambio, esto imposibilita la introducción de la moneda: “[...] sobre la base de la teoría del valor de uso y de la utilidad límite de Jevons y Menger" (Engels, 1894 [2002]: 13), prefacio al t. III del Capital de Marx.

${ }^{2}$ Que en el punto óptimo individual constituye la tasa marginal de sustitución, pues, el costo de oportunidad - pendiente de la recta presupuestal-, se iguala, en esta circunstancia, con la pendiente de la curva de indiferencia de la función de utilidad del individuo. En virtud de la implicación fundamental de la competencia, agentes tomadores de precios, este resultado formal de la optimización implica una paradoja, pues, a pesar de que las preferencias individuales sean distintas, todos los individuos tienen la misma tasa marginal de sustitución: "Pero dado que la tasa marginal de sustitución para cualquier par de bienes es igual a la razón de los precios para todos 
dominante, a saber, una expresión de trueque. Con fines didácticos o de representación gráfica del análisis de la oferta y la demanda de un mercado, puede asumirse una economía de dos mercancías, además de la homogeneidad de grado cero de las funciones de demanda neta. El resultado de este último supuesto es que el precio de una de las mercancías se transforma en el numerario del precio de la otra. Luego, debido a una de las consecuencias de la Ley de Walras, el equilibrio en un mercado garantiza el equilibrio del otro.

Por consiguiente, es pertinente preguntarse ¿tiene sentido el análisis del equilibrio parcial para un sistema económico con múltiples mercados? En el marco de la teoría de los precios de la teoría dominante la respuesta es negativa. No obstante, la aplicación del teorema Hicks-Leontief permite la construcción de un índice de precios para un bien compuesto de la economía global. A partir de este índice es posible asumir que el precio de una mercancía particular varía, mientras todos los otros precios permanecen constantes (cláusula ceteris paribus), esto permite aplicar el análisis del equilibrio parcial a ese mercado particular.

Adicionalmente, los aportes de Ragnar Frisch (1933), quien acuñó los conceptos de microeconomía y macroeconomía, unido a las contribuciones notables de Simon Kuznets, Colin Clark, y muy especialmente, los trabajos de uno de los economistas más relevantes del siglo xx, John Maynard Keynes, permitieron la construcción de estadísticas económicas agregadas de las cuentas nacionales e internacionales que hoy hacen posible el estudio teórico y empírico en el ámbito de la economía en su conjunto: la macroeconomía.

Por último, esta investigación tiene un único desacuerdo con Arrow y Hahn (1971). Ellos señalan que Cournot utilizó el análisis de equilibrio parcial, sin embargo, el estudio de la obra de este autor permite demostrar lo contrario. En efecto, Cournot, y posteriormente Marx, hicieron análisis de precios relativos, en los cuales la plata y el oro, respectivamente, funcionan como numerarios. En cambio, el equilibrio parcial asume precios absolutos, Arrow y Hahn argumentan esto con mucha claridad.

\section{EQUILIBRIO GENERAL VERSUS EQUILIBRIO PARCIAL EN EL MARCO DE LA TEORÍA DEL VALOR}

¿Qué significa el concepto equilibrio parcial? ¿Quién acuño este término? Marshall (1890, [1920]) retoma el ajuste vía cantidades de los clásicos, y propone una teoría de largo plazo del precio normal tal que la cantidad ofrecida se ajusta relativamente despacio. De hecho, Marshall ofrece una propuesta donde se necesita un

los individuos, es cierto también que la tasa marginal de sustitución entre dos bienes cualesquiera es la misma para todos los individuos" (Arrow, 1974: 256). 
largo plazo para estudiar el movimiento de los precios. A partir del análisis de la función de demanda que formuló Cournot (1838, [1897]), ${ }^{3}$ Marshall generó el análisis metodológico de la interacción de la oferta y la demanda de un mercado por la vía de una gráfica que reúne ambas funciones. Este equilibrio parcial propuesto por Marshall se alcanza en el punto donde ambas curvas se cruzan. ${ }^{4}$ Aunque de acuerdo con Google Books Ngram viewer, el término "equilibrio parcial" emergió en la década de los años 1920, probablemente fue Stigler (1942), quien acuñó dicho término: "Un equilibrio parcial es aquel que está basado en un único rango de datos, un ejemplo estándar es el precio de un único producto, los precios de todos los otros productos han quedado fijos durante el análisis".

Hay que señalar, en descargo de Marshall, que él estaba consciente de que el análisis de equilibrio parcial implica desechar los efectos ingreso y sustitución, por lo que se podrían descuidar dos factores subyacentes para resolver problemas reales. Sin embargo, a fin de validar su propuesta, argumentó que, las limitaciones intelectuales humanas para resolver cuestiones económicas complejas, lleva a utilizar ese tipo de simplificaciones. Independientemente de ello, a la luz de estas simplificaciones, los factores omitidos a lo largo del análisis del equilibrio parcial, en virtud de la cláusula filosófica ceteris paribus, evaden la medición precisa del tiempo del proceso de ajuste. Keynes (1936: 139) argumenta que Marshall "[...] retrocede cuando su argumento lo lleva a un terreno dudoso". Así, con el fin de construir el conocimiento económico, Marshall proporciona una notable enseñanza metodológica holística, ${ }^{5}$ destinada a un programa dinámico de investigación, distante del análisis de equilibrio parcial, donde los pasos analíticos son anteriores a la síntesis:

\footnotetext{
3 "Ahora tenemos que examinar las relaciones generales de la demanda y la oferta; especialmente aquellas que están relacionadas con ese ajuste de precio, por el cual se mantienen en 'equilibrio'. Este término es de uso común y puede ser utilizado aquí sin explicación especial. [...] tenemos que considerar el volumen de la producción auto ajustándose a las condiciones del mercado, y, así, el precio normal está determinado en la posición de equilibrio estable de la demanda normal y de la oferta normal": cita de Cournot a la que alude Marshall (1890, V).

${ }^{4}$ Este ajuste marshalliano inspiró la formulación de la idea de la tela de araña, la cual fue propuesta de manera independiente por Schultz (1930: 34); Tinbergen (1930) y Ricci (1930). Más tarde Kaldor (1934a y 1934b), lo llamó metafóricamente telaraña, cuyo teorema fue formulado por Ezekiel (1938). Hoy en día, se enseña, en algunos manuales microeconómicos, en términos de un ajuste, que depende de las pendientes de la función de oferta y demanda. Para más detalles, véase los documentos de Kaldor (1934a: 136; 1934b: 60-76): el análisis se construye bajo el supuesto de que los compradores "tienen un sistema definido de deseos y actúan de acuerdo [...] con los postulados generales de la teoría subjetiva del valor".

${ }^{5}$ Lo cual muestra la ambigüedad de este gran autor, tanto en torno a su análisis del equilibrio parcial, como su visión sobre la compleja interdependencia que encarna el equilibrio general.
} 
El elemento del tiempo es la causa principal de esas dificultades en las investigaciones económicas que hacen necesario que el hombre con sus poderes limitados vaya paso a paso, rompiendo un asunto complejo, estudiando una parte a la vez y así, finalmente, combinar sus soluciones parciales en una solución más o menos completa de todo el acertijo. Al romperlo, el hombre segrega esas causas inquietantes, cuyos disturbios resultan inconvenientes para el tiempo, y lo libra caminando rápidamente mediante la denominada Cateris Paribus. El estudio de un grupo de tendencias queda aislado por el supuesto de que otras cosas permanecen constantes: la existencia de otras tendencias no se niega, pero sus efectos perturbadores son ignorados por un tiempo. Cuanto más se reduce el problema, con más precisión se puede manejar: pero también menos se corresponde con la vida real. Cada manejo exacto y firme de un tema estrecho, sin embargo, ayuda a tratar asuntos más amplios, donde está contenida esa cuestión estrecha, con más precisión de lo que de otra manera habría sido posible. Con cada paso más cosas pueden librarse; las discusiones exactas se pueden hacer menos abstractas, las discusiones realistas se pueden hacer menos inexactas de lo que era posible en una etapa más temprana. (Marshall, 1890 [1920]: 366).

En un trabajo seminal para la crítica del equilibrio parcial, Sraffa (1926), estudió la interdependencia de los mercados al analizar las dos leyes de los rendimientos (crecientes y decrecientes). Dicho autor describe las condiciones necesarias para aplicar el análisis del equilibrio competitivo dentro del marco de la teoría del valor, en la medida que las demandas de dichos mercados están ligadas por la mutua sustitución. Como consecuencia de esto, las curvas de oferta y demanda no pueden ser aisladas ni reemplazadas unas por otras, para cada mercado particular, asumiendo la cláusula filosófica ceteris paribus, que conduce a la simetría de fuerzas de demanda y oferta de mercados aislados, como Marshall propone, al asumir que la formación del precio de una mercancía particular puede ser explicada por una grafica donde las curvas de oferta y demanda interactúan. De esta forma, Sraffa se convirtió en el precursor de la crítica del análisis del equilibrio parcial.

Las dificultades realmente graves aparecen cuando se considera hasta qué punto las curvas de oferta basadas en las leyes de los rendimientos cumplen las condiciones necesarias para poder emplearse en el estudio del valor de equilibrio de las mercancías individuales producidas en condiciones competitivas. Este punto de vista supone que las condiciones de producción y la demanda de una mercancía pueden considerarse, en lo que respecta a las pequeñas variaciones, como prácticamente independientes, tanto entre sí como en relación con la oferta y la demanda de todos las demás mercancías [ ...] cuando una variación de la cantidad producida por la industria de que se trate crea una fuerza que actúa directamente, no sólo sobre sus propios costos, sino 
también sobre los costos de otras industrias; en tal caso las condiciones del 'equilibrio particular' al que se pretendía aislar están distorsionadas, y ya no es posible, sin contradicción, descuidar los efectos colaterales [...] ya que las mercancías en cuya producción entra un factor especial común son, en cierta medida, sustitutas entre sí [...] la modificación de sus precios no tendrá efectos apreciables sobre la demanda de la industria en cuestión. (Sraffa, 1926: 535-539).

Sraffa concluye en desacuerdo con el método de Marshall, en la medida en que no refleja el concepto de costo de producción y engaña los procesos de formación de precios, así como la cantidad individual producida. Sraffa propone otro método para lograr el conocimiento de las fuerzas que conducen al equilibrio, sin perturbar la interdependencia del mercado, en consideración, con las leyes de los rendimientos, así como con otros mercados.

Lo importante es averiguar cómo se pueden agrupar las diversas fuerzas en el trabajo de la manera más homogénea, de modo que la influencia de cada una en el equilibrio resultante de su oposición pueda ser más fácilmente estimada [...], los métodos mencionados deben ser rechazados [...]. Además, altera de forma engañosa el significado acostumbrado y bien definido de la expresión 'costo de producción' [...]. En consecuencia, falsea la forma en que se ve afectado el proceso real de determinación del precio y de la cantidad producida por cada empresa (Sraffa, 1926: 544).

Arrow y Hahn (1971: 2) sostienen que, a pesar de que pueda ponerse en duda la consistencia del trabajo de Smith, este autor fue el creador de la teoría del equilibrio general y añaden (1971: 2-3) que:

los posteriores expositores sistemáticos del sistema clásico, como Ricardo, Mill y Marx, cuyo trabajo subsanó algunas lagunas lógicas del de Smith, pueden ser considerados los primeros expositores de la teoría del equilibrio general. En algunos sentidos, Marx se aproximó más a la teoría moderna [...] que cualquier otro economista clásico [...] El reconocimiento pleno del concepto del equilibrio general puede atribuirse sin lugar a duda a Walras.

Sin temor a cometer un error, debe señalarse que esta lista de autores que Arrow y Hahn ofrecen, sobre el análisis del equilibrio general, es incompleta, pues, falta Cournot; el primero en reconocerlo sería Walras (1874 [1900]: 37). Este trabajo se ocupa, más adelante, de rescatar tanto los aportes de Cournot, como los de Marx, en relación con la crítica al análisis del equilibrio parcial, pues, en el 
marco de la introducción del dinero a la teoría del valor, ambos criticaron el concepto de precios absolutos. ${ }^{6}$

En virtud de la naturaleza holística del sistema económico, el mecanismo de la oferta y la demanda en un mercado único no sólo depende de su precio relativo, sino que es consecuencia de la evolución de los precios relativos de la economía en su conjunto. Por consiguiente, no hay duda de que la teoría del equilibrio y desequilibrio general es filosófica y metodológicamente universal. En efecto, ambos fenómenos generales no pueden descomponerse en equilibrios y desequilibrios separados para mercancías y mercados individuales, los ajustes y desajustes de las magnitudes económicas, dependen del mecanismo de los precios de la economía en su conjunto, y no pueden ser separados en análisis parciales. Arrow (1972 [1974]: 254) lo hizo notar en su discurso nobel:

El adjetivo "general" se refiere al argumento de que no podemos hablar legítimamente de equilibrio con respecto a ninguna mercancía en particular; dado que la oferta y la demanda en cualquier mercado depende de los precios de otras mercancías, el equilibrio general de la economía no puede descomponerse en equilibrios separados para mercancías individuales.

El argumento de Arrow y Hahn puede ser fortalecido al invocar el método de análisis separado de los mercados con el cual inicia Walras su teoría del numerario, pues éste trae como consecuencia lógica y metodológica un resultado, de acuerdo con el cual, si existiera el equilibrio, éste muy posiblemente sería imperfecto.

Bajo las condiciones definidas anteriormente, existiría en el mercado un cierto equilibrio de las mercancías tomadas dos a dos; pero no sería más que un equilibrio imperfecto. El equilibrio perfecto o equilibrio general del mercado sólo tendrá lugar si el precio de una de dos mercancías cualesquiera en términos de la otra es igual al

${ }^{6}$ Erróneamente Arrow y Hahn (1971: 6) arguyen que Cournot es uno de los autores que utilizó el análisis del equilibrio parcial. Probablemente este desliz de Arrow y Hahn obedezca a que Marshall (1890 [1920]: 189) cita a Cournot en los términos siguientes: "Cuando se habla de la demanda y la oferta entre sí, es necesario que los mercados a los que se refieren sean los mismos. Como dice Cournot: 'Los economistas entienden por el término Mercado, no un mercado particular en el cual se compran y venden cosas, sino el conjunto de cualquier región en la que los compradores y los vendedores están en relaciones tan libres entre sí que los precios de los mismos bienes tienden a la igualdad fácil y rápidamente"'. Así, Cournot está haciendo referencia, anticipándose a Walras y Jevons, al problema de la unicidad del precio de equilibrio, pero no está haciendo un análisis de equilibrio parcial. 
cociente de los precios de estas dos mercancías en términos de una tercera mercancía cualquiera (Walras, 1874 [1900]: 157).

Por lo tanto, el equilibrio general no puede ser fragmentado en equilibrios separados de mercancías individuales. La existencia de un mercado para una mercancía en particular implica que al menos hay un mercado adicional más allá del primero. Por lo tanto, el concepto de precio absoluto no tiene sentido. Así, debido a la falta de dinero en la teoría subjetiva del valor, un precio individual se expresa como la tasa de cambio entre dos mercancías, en mutua relación, con respecto a transacciones de cantidades, $\frac{p_{i}}{p_{j}}=\frac{\Delta x_{j}}{\Delta x_{i}}$ por consiguiente, este precio relativo expresa un proceso
de trueque.

Podría argumentarse, en descargo del análisis del equilibrio parcial, que éste tiene implícito la cláusula filosófica ceteris paribus, si en lo que concierne a la variación de los precios, se asume que sólo cambia el precio de la mercancía que se quiere analizar. De esta forma, por la vía de estática comparativa, podría efectuarse un análisis de equilibrio parcial para ese mercado. Pero, este argumento es engañoso, y se colapsa fácilmente debido a la existencia de mercancías sustitutas y complementarias.

En efecto, una mercancía desempeña un doble papel (tiene una doble característica funcional), como sustituta en algunos casos, como complementaria en otros. Pero, además, cualquier variación del precio de una mercancía, conduce de forma explícita a la variación en el ingreso residual disponible, por lo tanto, el presupuesto para financiar la compra de otras mercancías también cambia. Así, las demandas y ofertas de las mercancías tienen una interdependencia general. Ambos efectos, de la variación del precio de un mercado, originan la interdependencia general de éstos y muestran que el concepto de precio absoluto no tiene sentido.

Debido a la existencia de mercancías sustitutas y complementarias, en algunas circunstancias podría existir la paradoja de la coexistencia de sustitución y complementariedad, que se corresponde con el hecho de que una mercancía es sustituta de otra, mientras que la segunda es complementaria de la primera. Mercancía 1 sustituta de la mercancía 2, por ejemplo, al mismo tiempo que, la mercancía 2 es complementaria de la mercancía 1. Por lo tanto, el equilibrio general requiere, al menos, de tres mercados con el fin de obtener la característica funcional dual sin la presencia de la paradoja, pues dos de ellos deben ser sustitutos (café y té, por ejemplo), y el tercero lleva a cabo un propósito complementario del primer par (azúcar, por ejemplo).

Formalmente es trivial la construcción de la paradoja; supóngase la existencia de dos mercancías, 1 y 2 , cuyas funciones de demanda están definidas 
por sus respectivos precios $p=\left(p_{1}, p_{2}\right), \mathrm{y}$ rentas $m_{1}$ y $m_{2}$, a saber, $x_{1}(p, m)=\frac{2 p_{1}-3 p_{2}}{m}, x_{2}\left(p, m_{2}\right)=\frac{2 p_{1}+3 p_{2}}{m_{2}}$. Por lo tanto, $\frac{\partial x_{1}(p, m)}{\partial p_{2}}<0$, lo cual implica que la mercancía 1 es complementaria de la mercancía 2, en cambio, $\frac{\partial x_{2}(p, m)}{\partial p_{1}}>0$, tiene una consecuencia inversa, pues en este caso la mercancía 2 es sustituta de la mercancía 1.

\section{Negación DEL EQUILIBRIO PARCIAL}

Es pertinente, ahora, analizar la prueba formal que permite mostrar el sinsentido subyacente en el concepto de equilibrio parcial. Es una prueba sencilla que define una función inversa de demanda de una mercancía: $f(p): R \rightarrow R$ :

Este tipo de análisis debe contemplarse como un instrumento pedagógico para tomar ventaja de la facilidad de la representación gráfica de relaciones de una sola variable [...] La existencia de un mercado presupone que debe haber, por lo menos, una mercancía aparte de la que se negocia en ese mercado, ya que un precio debe expresarse como la tasa de cambio a la cual un individuo renuncia a la mercancía en cuestión. Si realmente sólo hubiese una mercancía en el mundo, no habría ningún intercambio ni mercado (Arrow y Hahn, 1971 [1991]: 6-7).

En la teoría del equilibrio general, definida por Hicks (1939 [1946]) y Samuelson (1947), hay dos principios básicos basados en el análisis de la competencia. En primer lugar, el comportamiento de individuos optimizadores en presencia de los precios tomados como dados por esos agentes; en segundo lugar, el establecimiento de los precios de modo que, teniendo en cuenta el comportamiento individual, la oferta es igual a la demanda en cada mercado. La consecuencia de ese proceso competitivo es evaluada por el óptimo de Pareto y la asignación de los bienes que deviene del resultado de distribución. Así, los agentes comienzan con la dotación inicial, cuyo valor constituyen sus ingresos; de acuerdo con sus preferencias y restricción presupuestal, dichos agentes eligen la mejor canasta de bienes que pueden financiar con su renta, ver Samuelson (1970 [1971]: 273-288). 
Entonces, para una economía competitiva y descentralizada de $m$ individuos y $n$ mercancías, dado el vector de precios $p=\left(p_{1}, \ldots, p_{n}\right)$ y las dotaciones individuales $\bar{x}_{k}=\left(\bar{x}_{1 k}, \ldots, \bar{x}_{n k}\right), k=1, \ldots, m$, la demanda individual de la mercancía $i$, por parte del $k$-ésimo individuo es una función de los precios y la renta, $x_{i k}\left(p, m_{k}\right) \forall k, i$; tal que, la renta está determinada por el producto vectorial $m_{k}=p \bar{x}_{k}$ (valor de la dotación).

Cada individuo tiene un conjunto presupuestal de elecciones individuales que no debe exceder al ingreso: $B_{k}=\left\{x \backslash p x_{k} \leq p \bar{x}_{k}\right\} \forall k, i$. En virtud de que la renta es una función de los precios, $m_{k}(p)$, la demanda neta de la mercancía $i$, por parte del $k$-ésimo individuo, queda definida como una función exclusiva de los precios: $z_{i k}(p)=x_{i k}\left(p, m_{k}(p)\right)-\bar{x}_{i k} \forall k, i^{7}$. Por consiguiente, la función de demanda neta agregada de la $i$-ésima mercancía es $z_{i}(p)=\sum_{k=1}^{m} z_{i k}(p)$.

\section{II.1. Análisis gráfico}

El análisis del método gráfico para un mercado aislado es un análisis de equilibrio general para una economía ficticia de dos bienes. Así, supóngase una economía de dos mercancías, 1 y 2 , en la cual, para el análisis del mercado de la mercancía 1, se tiene como resultado endógeno que la mercancía 2 es el numerario. En efecto, si se asume la homogeneidad de grado cero de las funciones de demanda y oferta, éstas están determinadas por la razón de los precios. Es decir, si $z_{1}(\lambda p)=z_{1}(p) \forall \lambda>0$, entonces, para $\lambda=p_{2}^{-1}$, se tiene $z_{1}\left(\lambda p_{1}, \lambda p_{2}\right)=z_{1}\left(\frac{p_{1}}{p_{2}}, 1\right)$. Luego, por una de las consecuencias de la Ley de Walras, formulada por Lange (1942), ${ }^{8}$ el vector de precios de equilibrio,

${ }^{7}$ La variación de los precios tiene dos efectos, un efecto distributivo (efecto ingreso) y un efecto en la asignación de los recursos (efecto sustitución). Estos efectos se analizan en la ecuación de Slutzky, y debido a que el agente tiene que vender para poder comprar, entonces el análisis debe respetar el axioma de la preferencia revelada.

${ }^{8} \mathrm{Si}$ en un sistema de $n$ mercados, $n-1$ de ellos están en equilibrio, entonces, el $n$-ésimo mercado también estará en equilibrio. 
$p^{*}=\left(\begin{array}{c}p_{1}^{*} \\ p_{2}^{*}, 1\end{array}\right)$, en el mercado de la mercancía 1 , también garantiza el equilibrio en el mercado de la mercancía 2. ${ }^{9}$ Por el contrario, si $p \neq p^{*}$, el desequilibrio en el mercado de la mercancía 1 , implica desequilibrio en el mercado de la mercancía 2.

Por lo tanto, el análisis gráfico en el mercado de la mercancía 1, nunca puede ser justificado con independencia de lo que está sucediendo en el mercado de la mercancía 2. Si se supone que ambas son mercancías normales y ordinarias, es decir, se verifica la ley de la demanda, entonces, la gráfica de abajo, ${ }^{10}$ es un dispositivo valioso, en cuanto a la didáctica que se utiliza para introducir al estudiante en el análisis intuitivo del equilibrio y el desequilibrio del modelo de Arrow Debreu.

Cuando se hace el examen gráfico de equilibrio y desequilibrio de la mercancía 2, por las mismas razones, todo el análisis formal es análogo al anterior, v.g., para $\lambda=p_{1}^{-1}$. Por el supuesto de homogeneidad, la demanda neta $z_{2}\left(\lambda p_{1}, \lambda p_{2}\right)=z_{2}\left(1, \frac{p_{1}}{p_{2}}\right)$. De igual forma, debido a una de las consecuencias de la Ley de Walras, el equilibrio en el mercado de la mercancía $2, p^{*}=\left(1, \frac{p_{1}^{*}}{p_{2}^{*}}\right)$, también garantiza el equilibrio en el mercado de la mercancía 1. En cambio, $p \neq p^{*}$, implica el desequilibrio en el mercado de la mercancía 1.

${ }^{9}$ La variación de $p_{2}$ tiene un efecto exógeno, v.g., produce que la curva de demanda se desplace hacia la izquierda o hacia la derecha, en función de dos factores: 1) la sustituibilidad o complementariedad entre $x_{1}$ y $x_{2} ; 2$ ) el alza o la baja de $p_{2}$. Un análisis similar se corresponde con la curva de oferta.

${ }^{10}$ En virtud del análisis del pie de página 3, la altura de las líneas rojas, que es igual a la altura de sus respectivos precios, mide la tasa marginal de sustitución. Así, se añade a la cita de Arrow de dicho pie de página, lo siguiente: "Esto sugiere a su vez que no hay posibilidad de que dos individuos, o cualquier número de ellos, puedan ganar comerciando entre sí tras lograr un equilibrio competitivo" (Arrow, 1974: 256). 
Gráfica 1. Equilibrio y desequilibrio del mercado de la mercancía 1.

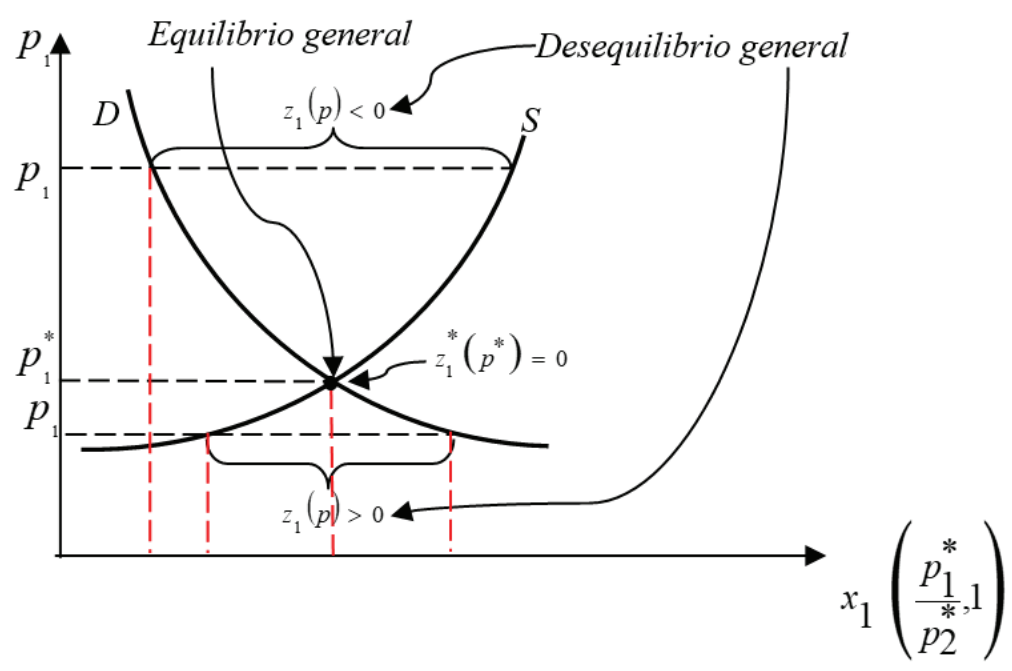

Mas-Colell, Whiston y Green (1995) le denominan equilibrio parcial a este análisis, al suponer que se estudia una mercancía (o grupo de mercancías), para el cual, el gasto de los consumidores constituye una proporción pequeña de sus presupuestos. En esa circunstancia, es razonable asumir que las variaciones de las magnitudes económicas en ese mercado no afectan significativamente los precios del resto de la economía (cláusula ceteris paribus). Por consiguiente, el efecto ingreso es insignificante. Así, el gasto en el consumo de todas las mercancías que no entran en el análisis es considerado gasto de una mercancía compuesta que permite la construcción del numerario. ${ }^{11}$ En este caso las funciones de utilidad del consumidor, que estos autores obtienen, son cuasilineales respecto del numerario. Sin embargo, estos autores examinan circunstancias en que este tipo de análisis puede extraviarse y llevar a resultados espurios Mas-Colell, Whiston y Green (1995: 538-539). Varian (1975), hace un análisis similar, para una economía de dos mercancías y $n$ consumidores; así, después de agregar las demandas y las rentas individuales de los consumidores, y asumir la cláusula ceteris paribus respecto de la renta agregada y el precio del bien 2, este autor construye la gráfica de la demanda del bien 1, y señala que:

${ }^{11}$ En la gráfica la mercancía compuesta sería la mercancía 2, el precio de esa mercancía (el numerario) sería un índice. 
a veces es útil concebir la demanda agregada como la demanda de un 'consumidor representativo' que tiene una renta que es la suma de las rentas de todos los individuos. Las condiciones en que puede utilizarse este supuesto son bastante restrictivas [...] Si partimos del supuesto del consumidor representativo [...] la demanda agregada de la economía es igual que la demanda de un individuo que se enfrenta a los precios $\left(p_{1}, p_{2}\right)$ y que tiene la renta $M$. Si mantenemos fijas todas las rentas monetarias y el precio del bien 2, podemos representar la relación entre la demanda agregada del bien 1 y su precio [...] esta curva se traza manteniendo fijos todos los demás precios y las rentas (Varian, 1975: 269-270).

Es precisamente la construcción de índices de las magnitudes económicas lo que se analizan a continuación, a fin de justificar el análisis del equilibrio parcial.

\section{ESPACIO TEÓRICO Y EMPÍRICO DEL ANÁLISIS DEL EQUILIBRIO PARCIAL: LA MACROECONOMÍA}

¿Existe alguna aplicación del equilibrio parcial en un sistema económico con múltiples mercancías? El teorema de agregación que, de manera independiente, formularon Leontief (1936) y Hicks (1939) proporciona la respuesta. Este teorema puede aplicarse al análisis del equilibrio parcial mediante la construcción de un índice de precios.

Así, se asume que los precios relativos de un conjunto de mercancías $X=\left\{x \in R^{l}\right\}$, permanecen constantes para efectos del análisis. El teorema supone que $X$ puede considerarse como un solo bien compuesto, cuyo precio, $\lambda$, es proporcional al precio $p_{i}$, de cualquier $x_{i} \in X, \lambda=\frac{p_{i}}{\overline{p_{i}}}$, donde $\bar{p}_{i}$ denota la constante de proporcionalidad, y cuya cantidad $q_{i}$ queda definida de tal manera que el valor del gasto en el bien compuesto, $\lambda X$, es igual a la suma de los gastos individuales del conjunto: $\sum_{i=1}^{n} \bar{p}_{i} q_{i}$.

O sea, el teorema establece que, si los precios de un conjunto de mercancías $X=\left\{x \in R^{l}\right\}$, satisfacen la condición $p_{i}=\lambda \bar{p}_{i} \forall i$, tal que $\bar{p}_{i}$ es constante, $i=1, \ldots, i, \ldots n$, mientras que $\lambda$, el precio del bien compuesto, puede variar, entonces, el valor de la cantidad del bien compuesto de la economía es una ponderación, $\sum_{i=1}^{n} \bar{p}_{i} q_{i}=\sum_{i=1}^{n} \frac{p_{i} q_{i}}{\lambda}$, de todas las cantidades de mercancías. 
Este teorema puede justificar el análisis de estática comparativa del equilibrio parcial cuando se modifique un único precio, en tanto todos los demás permanezcan constantes, pues estos últimos pueden ser considerados como mercancía común, cuyo precio es $\lambda$. Así, queda explícita la cláusula filosófica ceteris paribus, en términos del numerario, $\lambda$, lo cual permite concluir que los precios absolutos no existen, pues incluso en equilibrio parcial los precios siempre son relativos respecto del numerario, $\lambda$.

En el contexto histórico de la formulación de este teorema, en 1933 Ragnar Frisch acuñó los conceptos macroeconomía y microeconomía, época en la que también emergieron los extraordinarios trabajos empíricos de Kusnetz y la contribución de uno de los economistas más relevantes del siglo xx: Keynes.

El análisis micro-dinámico es un análisis con el cual tratamos de explicar con cierto detalle la conducta de una determinada parte del enorme mecanismo económico, dando por sentado que algunos parámetros generales están dados [...]. El análisis macro-dinámico trata, por otro lado, de explicar el sistema económico global, considerándolo en su conjunto [...]. Tal vez podamos empezar con el lanzamiento de todo tipo de producción en una variable, todo el consumo en otra, y así sucesivamente, imaginando que las nociones de 'producción', 'consumo', etcétera, se pueden medir por algunos tipos de índices totales (Frisch, 1933: 2-3).

Las itálicas de esta cita se han puesto a propósito para llamar la atención sobre las preocupaciones metodológicas que ocuparon a Frisch. Primero, la cláusula filosófica ceteris paribus está presente en el análisis microeconómico. Segundo, es irónico que entre las contribuciones de Frisch subyacen sus reflexiones metodológicas, en sus esfuerzos por hacer de la economía una disciplina precisa, con una estructura de variables cuantificables, lo cual difiere de la expresión tradicional "por un lado y por otro lado", donde el equilibrio de la respuesta que se busca queda en el aire.

\section{III.1. Una digresión histórica metodológica}

La generalizada pereza cultural de algunos economistas contemporáneos -formados en un ambiente de enseñanza aún más desorientada que la que Keynes (1933 [1951]) reclamaba en su artículo sobre Malthus- trae como consecuencia que su arrogancia, los lleve a desdeñar el estudio de las cuentas nacionales. ${ }^{12}$ Por esa razón,

${ }^{12}$ Los grandes referentes que sentaron los cimientos de la disciplina: Petty, Punfendorf, Law, Locke, Berkeley, Cantillon, Montesquieu, Hume, Quesnay, Turgot, Steuart, Smith, Ricardo, 
cuando estudian la Teoría General de Keynes, lo hacen de manera superficial y evaden, en particular, el estudio de los cuatro capítulos del Libro II: Definiciones e Ideas. En estos capítulos, el autor plasma la naturaleza de los agregados económicos que sustentan sus posteriores enunciados.

Lo poco satisfactorio de las unidades que emplean los economistas puede ejemplificarse por los conceptos de dividendo nacional, existencia (o acervo) de capital y nivel general de precios: 1) [...] la producción de mercancías y servicios realizada por la comunidad es un complejo no homogéneo, que no puede medirse, hablando en sentido estricto, excepto en casos especiales, como, por ejemplo, cuando todos los componentes de una producción entran en la misma proporción en otra producción. 2) La dificultad es mayor todavía cuando [...] tratamos de medir la adición neta al equipo de capital, porque es preciso encontrar alguna base cuantitativa de comparación entre las nuevas partidas del equipo producidas durante el periodo y las viejas que han desaparecido por desgaste [...] El problema de comparar dos producciones reales entre sí y de calcular después la producción neta, contraponiendo las nuevas partidas del equipo al desgaste de las viejas, origina acertijos que pueden calificarse de insolubles sin temor a equivocarse. 3) [...] el bien conocido pero inevitable elemento de vaguedad que [...] acompaña al concepto del nivel general de precios, hace a este término poco satisfactorio para $[\ldots]$ un análisis causal, que debería ser exacto [...] estas dificultades se consideran correctamente como 'acertijos' $[\ldots]$ nuestro análisis cuantitativo debe explicarse sin usar ningún término cuantitativamente vago [...] que nos impida realizar comparaciones estadísticas aproximadas que dependan de elementos amplios de juicio [...] Cuando con fines descriptivos o de comparación [...] deseamos referirnos a un aumento de la producción, debemos apoyarnos en el supuesto general de que el volumen de ocupación asociado a cierto equipo de capital será un índice satisfactorio del total de la producción resultante, suponiendo que ambos aumenten y disminuyan juntos, aunque no en una proporción numérica definida. Al tratar de la teoría de la ocupación me propongo, por lo tanto, usar solamente dos unidades fundamentales de cantidad, a saber, cantidades de valor en dinero y cantidades de ocupación. La primera es estrictamente homogénea y la segunda puede hacerse que lo sea $[\ldots]$ tomando una hora de empleo ordinario como unidad y ponderando una hora de trabajo especial proporcionalmente a su remuneración [...] una hora de trabajo especial remunerada al doble del tipo ordinario se contará por dos. Denominaremos unidad de trabajo a la unidad en que se mide el

Malthus, Marx, entre otros, adolecieron de lo que hoy es un privilegio en materia de información estadística, como criterio de demarcación que, invocando a Popper, hubiera permitido someter a prueba sus teorías. 
volumen de ocupación, y llamaremos unidad de salario al salario monetario de una unidad de trabajo [...] Si $E$ representa la nómina de salario [...] $S$ la unidad de salarios y $N$ la cantidad de empleo, $E=N S$ (Keynes, 1936: 65-68).

Las magnitudes económicas que Keynes (1936: 213) utiliza son tres: dinero, tiempo y empleo, la última es la única unidad de medida física. Así, por ejemplo, en el libro III que analiza los factores objetivos y subjetivos de la propensión a consumir, en el capítulo 8, que estudia los factores objetivos, al examinar la inversión y la inversión neta, Keynes invoca a Colin Clark y a Simon Kuznets, para comparar sus análisis y resultados estadísticos, de inversión e inversión neta, con los resultados de estos autores:

El hecho de que sea la inversión más bien que la inversión neta la que surja de las estadísticas de la producción se desprende en forma concluyente y natural de la obra [...] de Colin Clark. También muestra la gran proporción que guardan normalmente la depreciación, etc., con respecto al valor de la inversión [...]. Kuznets ha llegado a una conclusión muy parecida al compilar las estadísticas de la Formación Bruta del Capital [...] como él le llama a lo que yo considero inversión [...]. Kuznets ha descubierto también las dificultades de pasar de la inversión bruta a la neta [...], 'la dificultad de hacer correcciones al consumo de los bienes durables existentes no es únicamente la falta de datos. El mero concepto del consumo anual de bienes que duran cierto número de años adolece de ambigüedades'. Keynes (1936: 219-220).

Los tres problemas de la filosofía, de acuerdo con Bartley (1964: 3), son: el problema del conocimiento, el problema de la racionalidad, y la reconciliación del primero con el segundo. Las raíces de la filosofía de la ciencia descansan en dos bases antagónicas de la historia del pensamiento filosófico: racionalismo y empirismo. Durante los siglos XVI y XVII, Descartes, Spinoza y Leibniz, argüían por la vía del racionalismo que la razón, antes que la experiencia, era la fuente del conocimiento. A finales del siglo XVII y en el siglo XVIII, Berkeley, Locke y Hume, sostuvieron, en sentido opuesto a los racionalistas, que la experiencia era la causa del conocimiento. Mediante una revolución científica se llegó a una reconciliación de ambas posturas, esto trajo como resultado un método científico que propone teorías sobre bases de lógica inductiva, que se confirman o refutan a través de pruebas experimentales de las predicciones deductivas que se derivan de la teoría. Este método asume que la evaluación de las teorías o hipótesis proviene de la aplicación de reglas científicas que validan un enunciado, ya sea que éste haya sido inferido a partir de principios racionales (racional) o inferido mediante la evidencia (empírico). 
Así, por ejemplo, la teoría del equilibrio general establece enunciados hipotéticos deductivos apriorísticos -como los que hemos invocado en las primeras secciones de este artículo- con los cuales se pretende explicar el funcionamiento del capitalismo. Sin subestimar el gran valor de la teoría, sino, por el contrario, para fortalecerla, es obvio que el ámbito empírico es clave para tener el criterio de demarcación que permita falsear los enunciados teóricos. ${ }^{13}$ En este sentido el desarrollo del conocimiento estadístico ha jugado un papel clave que no se debe menospreciar. Keynes es un ejemplo, pues, a pesar de su vocación teórica, tuvo la cautela de que sus enunciados e hipótesis estuvieran libres de rasgos espurios. En una carta dirigida Roy Harrod en 1938, Keynes ofrece una definición de economía:

La economía es una ciencia que piensa en términos de modelos y un arte que escoge los modelos relevantes para el mundo contemporáneo [...]. Al contrario de las ciencias naturales, el objeto al cual se aplica es, en muchos aspectos, no homogéneo a través del tiempo. El objeto de un modelo es segregar los factores semipermanentes o relativamente constantes de aquellos que son transitorios o fluctuantes, y de esta forma desarrollar una vía lógica de pensar respecto a los últimos y entender en las series de tiempo los casos en que éstos se elevan. Los buenos economistas son escasos porque el don de emplear la 'observación vigilante' para seleccionar los buenos modelos es a todas luces sumamente escaso (Keynes, 1938 [1994]: 287).

Las estadísticas de las cuentas nacionales muestran que el consumo es un factor relativamente constante, en cambio, la inversión es bastante volátil. Este es un argumento que subyace en la cita anterior. Keynes tenía la información y la capacidad de leerla adecuadamente para elegir el modelo que se adecuaba a cada circunstancia.

\section{Un desacuerdo con Arrow y Hahn ACERCA de Cournot}

Cournot (1838 [1897]) niega acertadamente la existencia de precios absolutos, su análisis está auxiliado por la analogía de la variación de la distancia entre puntos y la variación de los precios de las mercancías. La clave de la propuesta de este autor está en formular una teoría que tiene incorporado un numerario que sirve como unidad de medida invariable de valor, además, dicha unidad de

${ }^{13}$ En efecto, la realidad, compleja por cierto, existe independientemente de nuestra conciencia, la construcción del conocimiento busca apropiarse de ésta, que Marx denomina concreto, por la vía de un proceso de introspección. 
medida es objetiva. Con absoluta razón, Cournot niega que pueda asignarse valor absoluto a una mercancía -este autor establece el sinónimo entre valor y precio-, de la misma forma que tampoco puede asignarse valor absoluto a una posición de un punto en el espacio. ${ }^{14}$

Cuando estos valores relativos cambian, concebimos claramente que la causa de esta variación puede hallarse en el cambio de uno de estos términos de la relación, o del otro término, o de ambos a la vez, lo mismo cuando la distancia entre dos puntos varía, la causa de este cambio puede residir en el desplazamiento de uno o de otro de los dos puntos o de ambos (Cournot, 1838 [1897]: 20).

Dada una economía de $n$ mercancías, v.g., un vector de precios $p=\left(p_{1}, \ldots, p_{i}, \ldots, p_{n}\right)$, Cournot niega, con justa razón, la existencia de $p_{i} \forall i$. En su lugar, este autor afirma que sólo puede existir $\frac{p_{i}}{p_{j}} \forall i, j$. El problema se complica al examinar la tasa de variación, $\Delta\left(\frac{p_{i}}{p_{j}}\right)$. En efecto, a partir la cita anterior, podría inferirse que este autor atribuye cambio en la distancia a tres razones: i) $\Delta p_{i}$; ii) $\Delta p_{j}$; iii) variación simultánea de $p_{i}$ y $p_{j}$, es decir, $\frac{\Delta p_{i}}{\Delta p_{j}}$. Sin embargo ¿qué sentido tienen $\Delta p_{i}$ y $\Delta p_{j}$ ? Si previamente Cournot ha negado la existencia de precios absolutos, hablar de la variación individual de éstos sería una contradicción en sus términos. Por consiguiente, la tercera fuente de variación que el autor propone es la que adquiere significado. Por esta razón, la conclusión de Cournot podría resultar engañosa a primera vista. "Distinguimos, pues, perfectamente los cambios relativos de valor que se manifiestan por la variación de los valores relativos, de las variaciones absolutas de valor de una o de otra de las mercancías entre las que el intercambio establece relaciones" (Cournot, 1838 [1897]).

${ }^{14}$ En vez de puntos puede usarse, sin pérdida de generalidad, la palabra planeta o estrella del universo para una ilustración más pedagógica. En realidad, Cournot extiende su analogía a las cuerdas sonoras musicales; pero, para los propósitos que aquí se requieren es suficiente con la analogía de distancia. 
Esta conclusión de Cournot, en cambio, tiene pleno sentido para la distancia entre dos objetos en un espacio específico, porque la distancia como unidad de medida es objetiva y universal. Una forma de resolver circunstancialmente el problema sería utilizar el concepto de precio de Walras (1874 [1900]: 87), Jevons (1871, [1970]: 139-143) y Edgeworth (1881: 21). Estos autores hablan de precios en términos de tasas de cambio, v.g., $\frac{p_{i}}{p_{j}} \equiv \frac{\Delta x_{j}}{\Delta x_{i}}$. En realidad, el pionero de este análisis es Cournot, Walras sería el primero en reconocerlo.

En particular, podría proponerse el numerario construido por Walras (éste es objetivo). Sería un paso adelante que ayudaría significativamente, porque trasciende el equilibrio parcial y se enfoca en un análisis de equilibrio general. Ese es precisamente el razonamiento de Arrow y Hahn con el cual se inició esta discusión. El numerario es un elemento clave porque su valor también puede variar. No obstante, el aspecto fundamental es la introducción del dinero en la teoría del valor, pues, si la teoría del valor es objetiva, el cambio de valor, en estas circunstancias, ocurriría por las tres posibilidades que apunta Cournot. Es aquí donde está el mérito de Marx, pues su análisis no requiere el numerario de una economía de trueque:

un cambio en el valor del oro en modo alguno afecta su función en cuanto patrón de precios. Por más que varíe el valor del oro, cantidades diversas de metal se mantienen siempre en la misma relación recíproca de valor. Aunque el valor del oro bajara en un 1000 por ciento, 12 onzas de oro valdrían, como siempre, 12 veces más que una onza de esa sustancia, y en los precios lo único que interesa es la proporción recíproca entre distintas cantidades de oro. Por otra parte, así como el peso de una onza de oro en modo alguno varía con la baja o el alza de su valor, tampoco se modifica el de sus partes alícuotas y de esta manera el oro, en cuanto patrón fijo de los precios, presta siempre el mismo servicio por más que cambie su valor (Marx, 1867 [1998]: 120)

En efecto, en este caso el valor podría cambiar por las tres razones que propone Cournot, a saber, $i$ ) variaciones en la cantidad de trabajo incorporado en la mercancía; ii) variaciones en la cantidad de trabajo incorporado en la moneda mercancía; iii) variación de la cantidad de trabajo incorporado en ambas. De esta manera, la variación de un sistema de precios relativos puede originarse por los tres escenarios ya apuntados, porque la falla de Cournot ha sido corregida por la moneda mercancía (oro o plata) que por naturaleza es objetiva. Cournot (1838 [1897]: 23-24), sin invocar la teoría del valor trabajo, pone sobre la mesa un argumento contundente que 
contraviene la idea que Arrow-Hahn tienen de él, de acuerdo con la cual éste efectuó un análisis de equilibrio parcial:

Basta $[\ldots]$ comparar $[\ldots]$ los valores de todas estas mercancías con relación a una de ellas [...]. Lo que verdaderamente importa es conocer las leyes que rigen las variaciones de valores [...]. En resumen, no existen más que valores relativos; buscar otros es caer en contradicción con la noción misma de valor intercambiable que implica necesariamente la de una relación entre dos términos.

El numerario es el elemento más estable. En un pie de página, Cournot (1838 [1897]: 25), lo señala de forma notable: "Lo que caracteriza el contrato de venta [...] del contrato de cambio es la invariabilidad del valor absoluto de los metales monetarios". Cournot también advierte que este no es el caso del papel moneda, por eso hace la distinción entre venta y cambio.

Pero si ninguna mercancía se encuentra en las condiciones requeridas por la perfecta fijeza, podemos, debemos imaginar una que no tendrá más que una existencia abstracta, pero también que no figurará más que como un término auxiliar de comparación destinado a facilitar la inteligencia de la teoría, salvo a desaparecer de las aplicaciones finales. De esta forma los astrónomos imaginan un sol medio, dotado de un movimiento uniforme; $y$, refiriendo sucesivamente a este astro imaginario tanto el sol verdadero como los otros cuerpos celestes, concluyen finalmente la situación real de estos astros con relación al sol verdadero (Cournot, 1838: 26).

Cournot enfrentó el reto de construir una unidad invariable de medida de valor abstracta, y se percató que este desafío había sido emprendido por Montesquieu (1748 [1752]: 412-413), antes que Ricardo (1817 [1821]fue : 33-35). Por esa razón, Montesquieu y no Ricardo es su referente analítico.

El precio se forma al comparar todas las mercancías unas con otras. Por eso no se tiene una moneda en particular; sino cada clase de mercancía es moneda de la otra [...] con esta manera de valuar las cosas [...] todas las mercancías o manufacturas de un Estado, $[\ldots]$ podrían ser valuada a través de un cierto número de amuletos; $y$, dividiendo el dinero de este Estado en tantas partes como amuletos existan, una parte de esta división de dinero tendrá el signo de un amuleto (Montesquieu, 1748 [1752]: 412).

Marx (1867), de manera independiente, pulió esta idea al eliminar el carácter abstracto de esa unidad de medida. El equivalente general -el oro, moneda mercancía con valor intrínseco-, es, sin lugar a duda, la unidad invariable de 
medida de valor objetivo. ${ }^{15}$ En efecto, los precios de la economía tienen un numerario universal, a saber, la moneda mercancía de Marx, cuyo objetivo es proporcionar a las mercancías la sustancia a través de la cual se expresan sus valores. ${ }^{16} \mathrm{Si}$ todos los precios son monetarios, entonces, dada una unidad moneda mercancía $q_{0}$ (una onza de oro, por ejemplo), en virtud de la diferencia en tecnología para su producción en las minas de oro, tendrá incorporada una cantidad de trabajo promedio, con valor $q_{0}$. De la misma forma, el vector de valores de las mercancías de la economía, $q=\left(q_{0}, q_{1}, \ldots, q_{i}, \ldots, q_{n}\right),{ }^{17}$ contiene una cantidad promedio de tiempo trabajo incorporado. Al dividirse en partes alícuotas cada una de las mercancías, la unidad de medida se convierte en patrón de precios (patrón de medida en peso, en el caso del oro), denotados por $P=\left(p_{0}, p_{1}, \ldots, p_{i}, \ldots, p_{n}\right) \cdot{ }^{18}$

una libra sirve como unidad de medida, y mientras que por una parte se la subdivide en onzas, etc., por la otra se suman libras hasta formar un quintal, etc. En toda la circulación metálica, por consiguiente, las denominaciones del patrón de peso, preexistentes, son también los nombres originarios del patrón dinerario o patrón de los precios (Marx, 1867 [1998]: 119).

Por consiguiente, si se define un número real $\lambda>0$, tal que, en términos del patrón de precios $\lambda=p_{o}^{-1}$, el vector de valores relativos de la economía queda definido por $\bar{P}=\left(1, \frac{p_{1}}{p_{0}}, \ldots, \frac{p_{i}}{p_{0}}, \ldots, \frac{p_{n}}{p_{0}}\right)$. Indudablemente, la unidad invariable de medida de valor, el equivalente general ${ }^{19}, q_{0}$, permite que $\bar{P}$ exprese objetivamen-

${ }^{15}$ La moneda como numerario. Menger (1871: 280) niega que el dinero sea una medida invariable de valor, porque sostiene, al igual que Jevons y Walras, una teoría subjetiva de valor.

${ }^{16}$ Invocando la ficción de Borges: "Pierre Menard autor del Quijote", podría colocarse, en la historia del pensamiento económico, a Marx como antecesor de Cournot.

${ }^{17}$ Cada una de ellas medidas en unidades específicas: lineales, de área, de volumen, de peso, de tiempo, etcétera.

${ }^{18}$ Marx establece una diferencia terminológica precisa entre dos conceptos, a saber, la medida de los valores y patrón de los precios, y advierte que "En las obras de autores ingleses, es indecible la confusión que reina entre medida de los valores y patrón de los precios. Constantemente se confunden las funciones, y por tanto los nombres". Marx ((1867 [1890]: 74).

${ }^{19}$ En efecto, el oro es una unidad de medida invariable de valor: "si el oro puede servir como medida de los valores, ello se debe únicamente a que él mismo es producto del trabajo, y, por lo tanto, potencialmente, un valor variable [...]. El cambio en el valor del oro tampoco obsta a su función como medida de valor. Dicha variación afecta simultáneamente a todas las mercancías, dejando por tanto inalterados, cateris paribus [si las restantes condiciones no varían], sus valores 
te la diferencia de valores de las distintas mercancías de la economía en términos monetarios. Lo que se intercambia con moneda son cantidades de trabajo incorporadas en las mercancías, con relación a la cantidad de trabajo incorporada en el numerario, $\frac{p_{i}}{p_{o}}=\frac{\Delta q_{o}}{\Delta q_{i}}$.

La homogeneidad de grado cero de las funciones de exceso de demanda, que Arrow y Hahn analizan, tienen implícito el concepto de neutralidad del dinero bajo ciertas restricciones. Así, si $z_{i}\left(\lambda p_{0}, \lambda p_{1}, \ldots, \lambda p_{i}, \ldots, \lambda p_{n}\right)=z_{i}\left(1, \frac{p_{1}}{p_{0}}, \ldots, \frac{p_{i}}{p_{0}}, \ldots, \frac{p_{n}}{p_{0}}\right)$, entonces todos los precios de la economía tienen la misma flexibilidad frente a variaciones de la cantidad de dinero, $\frac{\Delta q_{0}}{\Delta q_{i}} \frac{q_{i}}{q_{0}}=\varepsilon_{i i} \forall i=1, \ldots, n$ (la elasticidad precio monetario constante), ${ }^{20}$ sobre la base de estas hipótesis, la moneda no influirá en las variables reales de la economía. La descripción de la economía de trueque que asume Montesquieu incorpora la posibilidad de neutralidad del dinero con crecimiento de los precios; pero también contempla la posibilidad de efectos monetarios reales uniformes sobre todas las mercancías.

Si suponemos que la cantidad de producción de un Estado se duplica, será necesario duplicar el producto de amuletos; pero si al duplicar la producción se duplica también el amuleto, la proporción permanecerá igual que antes de haber duplicado cada uno de éstos. Si, puesto que, con el descubrimiento de las Indias, el oro y la plata se han incrementado en Europa en una proporción 1 a 20, los precios de las provisiones y las mercancías deben haber aumentado en una proporción 1 a 20. Pero si, por otro lado [...] el incremento de la cantidad de mercancía a crecido en una proporción 1 a 2 [...] afirmo que esto necesariamente conduce, a que la proporción es solo de 1 a 10 (Montesquieu, 1748 [1752]: 412-413).

relativos recíprocos, aun cuando todos se expresen ahora en precios áureos superiores o inferiores a los de antes". Marx (1867 [1998]: 120)

${ }^{20}$ Sea $R_{i}=P_{i} q_{i}$ el valor de la transacción de la mercancía $i$. En virtud de que la elasticidad de sustitución, $\varepsilon_{i}$, es constante, dicho valor de las transacciones no se altera cuando varía el precio de dicha mercancía: $P_{i}$. En efecto, la solución de la ecuación diferencial es $P_{i}=R_{i} P_{i}{ }^{-\varepsilon_{i}}$, donde $\mathrm{R}_{\mathrm{i}}$ es la constante de integración. 
Al respecto, es importante señalar que Lange (1944), señala que el factor de proporcionalidad de variación de los precios -él le llama flexibilidad de los precios-, generalmente difiere de una mercancía a otra, entonces, el argumento de neutralidad del dinero no se sostiene; Pufendorf (1673); Cantillón (1755 [1931]); ${ }^{21}$ Marx (1867); Keynes (1930,); Hayek (1931 y 1939), y Spengler (1954) argumentan en la misma dirección.

Los precios de las mercancías sólo pueden aumentar de manera generalizada si se mantiene constante el valor del dinero y aumentan los valores de las mercancías o si, permaneciendo éstos inalterados, el valor del dinero baja. Y a la inversa. Los precios de las mercancías sólo pueden bajar de manera generalizada si no varía el valor del dinero y descienden los valores mercantiles, o si éstos se mantienen constantes y aumenta el valor del dinero. En modo alguno se sigue de esto que un mayor valor del dinero traiga consigo una baja proporcional en el precio de las mercancías, y un valor menor del dinero un alza proporcional en el precio de las mismas. Esto sólo rige para mercancías de valor inalterado. Las mercancías, por ejemplo, cuyo valor asciende en la misma medida y al mismo tiempo que el valor del dinero, conservan incambiados sus precios. Si su valor aumenta más lenta o más rápidamente que el del dinero, la baja o el alza de sus precios estará determinada por la diferencia entre el movimiento de su valor y el del dinero, etcétera (Marx, 1867: 121).

\section{CONCLUSIONES}

En la teoría de los precios el equilibrio y el desequilibrio económico general son conceptos filosófica y metodológicamente universales en términos de la interdependencia general de un sistema de mercados. La descomposición analítica, de ambos conceptos, en equilibrios y desequilibrios aislados desemboca en falacia de composición. La formación y la variación de las magnitudes económicas provienen de un sistema complejo holístico de interdependencia general; por consiguiente, los precios absolutos no existen, éstos siempre son relativos.

Por su naturaleza holística, la explicación del funcionamiento del conjunto de ofertas y demandas individuales del sistema de un mercado particular no puede inferirse a partir de la agregación de análisis aislados de cada una de las ofertas y demandas de dicho mercado, pues, el sistema de oferta y demanda

${ }^{21}$ Spengler (1954: 283) señala que Hume, quien argüía que conocía el trabajo de Cantillón, olvidó "la importancia del brillante análisis de Cantillón (que se compara favorablemente con el de Keynes) respecto a la respuesta de la estructura de precios frente a los cambios en la cantidad de dinero". 
agregada tiene propiedades que los sistemas de ofertas y demandas individuales no tienen: el todo es más que la suma de las partes. Así, por ejemplo, asumir la ficción de un agente representativo, cuyo ingreso es equivalente al agregado de los ingresos individuales desvirtúa la distribución del producto social entre aquellos que contribuyen a crearlo. Dada la distribución del producto social entre aquellos que contribuyen a crear dicho producto, la demanda individual de un producto específico influye sobre el ingreso individual de quien ofrece dicho producto. ${ }^{22}$

Esta es una verdad filosófica trivial y evidente. El error de enunciar como principio de alcance general, algo que se desprende a partir de una propiedad de un subconjunto, en términos de un rasgo general del conjunto, se denomina falacia de composición. El equilibrio parcial adolece de esta falacia filosófica, pues, la forma en que se comporta un individuo ante la variación del precio de la mercancía que ofrece o demanda, no puede ser extendida al comportamiento de todos los individuos. Así, la oferta y la demanda de cada uno de ellos tiene distinto grado de flexibilidad (elasticidad precio); y lo mismo ocurre con respecto a la elasticidad renta individual.

Esto también se extiende al sistema económico en su conjunto. Así, la oferta y la demanda de cada uno de los mercados tienen distinto grado de flexibilidad frente a la variación de sus respectivos precios monetarios. Develar esta falacia de composición permite entender, la no neutralidad del dinero que formulan Spengler (1954), Langue (1944), Hayek (1931 [1932]; 1939), Keynes (1930), Marx (1867), Cantillon (1755 [1931]) y Pufendorf (1673).

A la luz de ese asombroso argumento de Marshall citado en la página 8, es posible obtener varias conclusiones que se traducen en una ambigüedad, tanto del propio autor, como de aquellos que elogian su enfoque de interdependencia general o critican su análisis de equilibrio parcial. En primer lugar, Marshall propone un enfoque analítico holístico, mediante el cual abandona el análisis de equilibrio parcial, y, gradualmente conduce a la interdependencia general. En segundo lugar, bajo esta perspectiva metodológica, Marshall debería ser, sin duda, un economista de equilibrio general. Tercero, Robins (1998: 306) sostiene que no tiene sentido decir que Marshall no era un teórico del equilibrio general; Colander (1995), apela al análisis complejo del sistema de grandes tendencias económicas agregadas y apunta en la misma dirección; aunque al mismo tiempo, Marshall simboliza, por excelencia, al economista del análisis de equilibrio parcial. En dirección diametralmente opuesta, Samuelson (1967) arguye que "las ambigüedades de Alfred Marshall paralizaron a los mejores cerebros de la rama anglosajona de nuestra profesión

${ }^{22}$ Véase el prólogo a la Edición Francesa de la Teoría General de Keynes. 
durante tres décadas". Estoy en deuda con Colander (1995), quien me facilitó su artículo donde encontré esta cita de Samuelson.

En efecto, a pesar de que Marshall tuvo una perspectiva de equilibrio general en la investigación económica, este autor no pudo construir un modelo de equilibrio general. En la Nota XXI de Marshall, en el apéndice matemático de sus Principios, donde analiza una economía con $n$ mercancías y $m$ factores, intenta alcanzar $m+n$ precios de equilibrio. Marshall obtuvo una solución paradójica de la cual parece no estar consciente, pues, su solución establece precios relativos, sin dinero ni numerario, ni precios absolutos. Este problema supuestamente había sido "resuelto" por Walras (1874) en la Parte III, Lección 11. En realidad, la solución fue obtenida por Arrow y Debreu (1954: 265-290), ${ }^{23}$ después de un largo tiempo de contribuciones históricas, particularmente tres aportaciones de Wald (1934 [1968]), (1935 [1968]), (1936 [1951]), y el trabajo de von Neuman (1937 [1945]). En cualquier caso, a pesar de su ambigüedad respecto del equilibrio parcial y general, Marshall fue un gran economista en la historia del pensamiento económico, que representa un punto de inflexión entre la vieja y la nueva economía política neoclásica con un enfoque heurístico, que él llamó economía, renombrando así a la disciplina al sustituir el concepto de Economía Política.

El trabajo seminal de Sraffa (1926) muestra, a través del análisis de las dos leyes de los rendimientos (crecientes y decrecientes), las profundas consecuencias perturbadoras de estas leyes sobre la simetría del equilibrio de la oferta y la demanda de un mercado aislado del resto de los mercados, que, por la vía de la cláusula filosófica ceteris paribus, asume Marshall. Esta constituye la primera crítica inobjetable al análisis del equilibrio parcial.

Adicionalmente, la variación de los precios en un mercado particular influye directamente en el resto de los mercados de la economía. Por consiguiente, es un error evadir el dominio de esta interdependencia general. En efecto, estas variaciones de los precios tienen un doble efecto, cuyos impactos se manifiestan no sólo en el mercado donde ocurren, sino también en el resto de los mercados de la economía, es decir, efectos en la asignación de los recursos, así como los efectos distributivos que argumentan Arrow y Hahn. Adicionalmente, en este trabajo, se añadió el análisis de la existencia de bienes complementarios, los cuales están estrechamente vinculados con esos efectos en la asignación de los recursos y de la variación de los precios que Arrow y Hahn apuntan. La cláusula filosófica ceteris paribus no puede evadir estas circunstancias, independientemente que se asuma que sólo varían las magnitudes económicas de un mercado particular.

\footnotetext{
${ }^{23}$ Aunque debe señalarse la gran limitación que representa la ausencia del dinero en esta demostración. Ambos autores son los primeros en reconocer esta limitante.
} 
Por lo tanto, el equilibrio parcial se convierte en algo superficial que no se corresponde con los hechos económicos. El efecto que se derrama sobre todos los mercados debido a la variación de las magnitudes económicas en un mercado particular es evidente por dos razones. Primero, como señalan Arrow y Hahn, los efectos distributivos en el mercado afectado alteran el ingreso residual disponible para financiar las compras en el resto de los mercados. Segundo, como ha sido argumentado en este trabajo, los mercados también tienen una interdependencia general, debido a la existencia de sustitutabilidad y complementariedad entre los bienes. Así, frente una única variación de las magnitudes económicas en un mercado particular, la cláusula filosófica ceteris paribus, no puede evadir esta clase de fallas.

No obstante, sin que se elimine por decreto la interdependencia general de los mercados, existe en la macroeconomía, teórica y aplicada, un espacio para el análisis del equilibrio parcial. En efecto, la macroeconomía es una rama de la teoría económica, que asume la cláusula ceteris paribus, a partir de la cual se construyen agregados estadísticos que confirman el funcionamiento de la economía global, si se tiene la cautela y honradez profesional de utilizar con pertinencia la información estadística.

Al rastrear el surgimiento del concepto de equilibrio parcial no está claro quién fue el autor que acuñó este término. Probablemente fue Stigler (1942), aunque de acuerdo con la búsqueda efectuada en Google Books Ngram viewer, este concepto emerge en la década de los años 1920, lo cual coincide con la última edición de los Principios de Marshall (1920) y la muerte de este autor. Coincide, también, con la publicación del artículo de Sraffa (1926). De cualquier forma, lo que resulta fundamental destacar es que en la disciplina se utiliza este concepto, sin tener no sólo cuidado respecto de su origen, sino, lo más lamentable, sin reparar en las inconsistencias de éste dentro del marco de la teoría del valor. Este trabajo muestra que esto último es un absurdo en virtud de la inexistencia de los precios absolutos. Es decir, en el mercado de zapatos, el precio zapato no existe, lo que existe es un precio monetario relativo, zapato por dinero y dinero por zapato, en la transacción de compra-venta en el cual el dinero es el numerario.

Cournot es un referente clave para entender la conclusión anterior, pues dicho autor niega la existencia de precios absolutos. Por esa razón discrepamos de Arrow y Hahn sobre su afirmación, según la cual, Cournot es un autor identificado con el análisis del equilibrio parcial. Sin embargo, es Marx el autor que permite entender que los precios son relativos en virtud de su naturaleza monetaria, pues la moneda mercancía, oro, es, por su naturaleza, la unidad de medida invariable de valor y el patrón de precios. Así, se intercambia una mercancía por otra, en términos de cantidades de trabajo promedio incorporadas en la transacción de 
ambas, una de las cuales es moneda (la compra y la venta), en virtud de que subyace la teoría objetiva del valor: valor trabajo.

\section{REFERENCIAS BIBLIOGRÁFICAS}

Arrow, Kenneth (1974), "General Economic Equilibrium: Purpose, Analytic Techniques, Collective Choice", The American Economic Review, vol. 64, núm. 3, pp. 253-272.

Arrow, Kenneth y Debreu, Gerard (1954), "Existence of Equilibrium for a Competitive Economy", Econometrica, vol. 22, núm. 3, pp. 265-290.

Arrow, Kenneth J. y Frank, H. (1971 [1991]), General Competitive Analysis, San Francisco/Edinburgh, Holden-Day, Inc.- Oliver\&Boyd.

Bartley, William (1964), "Rationality versus the Theory of Rationality", en Bunge, Mario (ed.), The Critical Approach to Science and Philosophy, pp. 3-31.

Borges, Jorge Luis (1998), Collected Fictions, Andrew Hurley (trad.), Toronto, Penguin Classics Deluxe Edition.

Cantillon, Richard (1755 [1931]), Essai sur la natrure du commerce en général, ed. de Higgs, Henry, Londres, Macmillan for the Royal Economic Society.

Colander, David (1995), "Marshallian General Equilibrium Analysis", Eastern Economic Journal, vol. 21, núm. 3, pp. 281-293.

Cournot, Augustin (1838 [1897]), Researches into the Mathematical Principles of the Theory of Wealth, Bacon, Nathaniel T. (trad.), con una bibliografía de economía matemática de Fisher, Irving, Londres, Macmillan.

Edgeworth, Francis Ysidro (1881), Mathematical Psychics, an essay on the application of mathematics to the moral sciences, Londres, C. Kegan Paul \& Co.

Ezekiel, Mordecai (1938), "The Cobweb Theorem", The Quarterly Journal of Economics, vol. 52, núm. 2, pp. 255-280.

Frisch, Ragnar (1933), "Propagation problems and impulse problems in dynamic economics", Economic Essays in Honour of Gustav Cassel, Universitetets, konomiske Institutt, Publikasjon nr.3., Reprinted from (London: George Allen \& Unwin).

Hayek, Friedrich A. (1931 [1932]), Prices and Production, George Routledge \& Sons, Second Revised and Enlarged Edition.

(1939), Profits, Interest and Investment, 1a. ed., Londres, George Routledge \& Sons Ltd. 
Hicks, John Richard (1939 [1946]), Value and Capital, 2a. ed., Oxford University Press.

(1940), "The Valuation of the Social Income", Economica, vol. 7, mayo, pp. 105-124.

Jevons, William Stanley (1871 [1970]), The Theory of Political Economy, introd. de Collison Black, R. D., Harmondsworth, Penguin Books.

Kaldor, Nicholas (1934), "A Classificatory Note on the Determinateness of Equilibrium”, The Review of Economic Studies, vol. I, núm. 2, pp. 122-136. (1934), "The Equilibrium of the Firm", The Economic Journal, vol. 44, núm. 173, pp. 60-76.

Keynes, John Maynard (1930), A Treatise on Money, Londres, Macmillan. (1933 [1955]), Robert Malthus: The First of the Cambridge Economists. The Collected Writings of John Maynard Keynes, Londres, Macmillan. (1936), Teoría general de la ocupación, el interés y el dinero, México, Fondo de Cultura Económica.

(1938), "Letter to Harrod of 4 July 1938", The Philosophy of Economics, an Anthology, 2a. ed., ed. de M. Hausman, Daniel, 1994, Cambridge University Press.

Lange, Oskar (1942), "Say Law: A Restatement and Criticism", Lange et al. (eds.), Studies in Mathematical Economics and Econometrics, University of Chicago Press, pp. 49-68.

(1944), Price Flexibility and Employment, Bloomington, The Principia Press.

Leontief, Wassily Wassilyovich (1936), "Composite commodities and the problem of index numbers", Econometrica, núm. 4, pp. 39-59.

Marshall, Alfred (1890, [1920]), Principles of Economics, An Introductory Volume, Macmillan.

(1996), The Correspondence of Alfred Marshall, Economis, vol. II: At the Summit, 1891-1902, ed. de Whitaker, John K., Cambridge University Press.

Marx, Karl (1867), El Capital, t. I, vol. 1, México, Siglo XXI Editores. (1867 [1890]), Capital, vol. 1, introd. de Cole, G. D .H., Eden y Cedar Paul (trads.), J. M. Dent \& Sons, 1946, reimp. de la 1a. ed. de 1930. (1894 [2002]), El Capital, t. III, vol. 6, México, Siglo XXI Editores.

Mas-Colell, Andreu; Whinston, Michel y Green, Jerry (1995), Microeconomic Theory, Oxford University Press. 
Menger, Carl (1871 [2007]), Principles of Political Economy, introd. de F.A. Hayek, The Institute for Human Studies, New York University Press, 1994, Libertarian Press (reimp. de la ed. de 1976).

Montesquieu Barón de, Charles De Secondat (1748 [1752]), The Spirit of Laws, Batoche Books, Kitchener 200, Ontario, Canadá.

Neuman, J. von (1937 [1945]), Translated by Karl Menger as "A model of general equilibrium", Review of Economic Studies, 13, (1945-6), pp. 1-9.

Pufendorf, Samuel von (1673 [1991]), De Officio Hominis et Civis, trad. por Silverthorne como On the Duty of Man and Citizen According to Natual Law, J. Tully ed., Cambrige University Press.

Ricardo, David (1817 [1821]), Principios de economía política y tributación, 3a. edición, 2a. reimp. 1973, México, Fondo de Cultura Económica.

Ricci, H. (1930), "Synthetische Okonomie", von Henry Ludwell Moore, Zeitschrift fuir Nationalokonomie, Wien, Band 1, Heft 5, 1930.

Robbins, Lionel (1998), A History of Economic Thought, Steven G. Medema y Warren J. Samuels (eds.), Princeton University Press (The LSE Lectures). Samuelson, Paul (1947), Foundations of Economic Analysis, Cambridge University Press.

(1967), “The Monopolistic Competition Revolution”, Kuenne, R. E. (ed.), Copetitition Theory, New York, John Wiley.

(1970), "Maximum Principles in Analytical Economics", Lex Prix Nobel in 1970, Estocolmo, P.A. Norstedt \& Soner, 1971, pp. 273-288.

Schultz, Henry (1930), Der Sinn der Statistischen Nachfragen, Heft 10, Veroffentlichungen der Frankfurter Gesellschaft fur Konjunkturfor- schung, Kurt Schroeder Verlag, Bonn.

Spengler, J. J. (1954), "Richard Cantillon: the First of the Moderns", Journal of Political Economy, 62 (parte I), pp. 281-295, (parte II) pp. 406-424.

Sraffa, P. (1926), “The Laws of Returns under Competitive Conditions", Economic Journal, vol. 36, núm. 144, pp. 535-550.

Stigler, G. (1942), The Theory of Competitive Price, New York, Macmillan. The Cambridge Dictionary of Philosophy 1995[1999], General Editor: Robert Audi, Second edition 1999, $11^{\text {th }}$ printing 2009, Cambridge University Press.

Tinbergen, J. (1930), Bestimmung und Deutung von Angebotskurven, Ein Beispeil, Zeitschrift fur National Okonomie, Wien, Band 1, Heft 5, 1930.

Varian, R. H. (1987), Intermediate Microeconomics, W. W. Norton \& Company, First Edition. 
Wald, A. (1934 [1968]), "On the Unique Non-Negative Solvability of the New Production Equations. Part I", Precursors in Mathematical Economics, W. J. Baumol y S. M. Goldfeld (eds.), Londres, London School of Economics (Series of Reprints of Scarce Work in Political Economy, 19). (1935 [1968]), "On the Production Economic Value Theory, Part II", Precursors in Mathematical Economics, W. J. Baumol y S. M. Goldfeld (ed.), Londres, London School of Economics (Series of Reprints of Scarce Work in Political Economy, 19). (1936 [1951]), "On Some Systems of Equations in Mathematical Economics”, Econometrica, núm. 19.

Walras, L. (1874 [1900]), Elements of Pure Economics or the Theory of Social Wealth, trad. William Jaffé (1954), 2a. reimp. 1965, Estados Unidos, Richard D. Irwin, INC. 